DOI : $10.24127 /$ biolova.v3i1.1779

\title{
PENGEMBANGAN MODEL PEMBELAJARAN JELAJAH ALAM SEKITAR (JAS) PADA MATERI KEANEKARAGAMAN HAYATI SEBAGAI SUMBER BELAJAR KELAS X DI SMAN 1 CUKUH BALAK
}

\author{
Apridayani ${ }^{1}$,Hening Widowati ${ }^{2}$ Achyani $^{3}$ \\ ${ }^{1}$ SMAN 1 Cukuh Balak, ${ }^{2,3}$ Universitas Muhammadiyah Metro \\ 1apridayani563@gmail.com, ${ }^{2}$ hwummetro@gmail.com. ${ }^{3}$ acysbd@gmail.com.
}

\begin{abstract}
Abstrak : Tujuan penelitian: (1) menghasilkan produk model pembelajaran Jelajah Alam Sekitar pada materi Keanekargaman Hayati sebagai Sumber Belajar Kelas X di SMAN 1 Cukuh Balak, (2) mengetahui tingkat kepraktisan model pembelajaran Keanekargaman Hayati berbasis Ekosistem Mangrove dan (3) mengetahui tingkat keefektifan model pembelajaran Keanekargaman Hayati berbasis Ekosistem Mangrove. Research and development adalah Penelitian yang digunakan dalam mengembangkan model pembelajaran Keanekargaman Hayati berbasis Ekosistem Mangrove sebagai Sumber Belajar Kelas X di SMAN 1 Cukuh Balak tahun pelajaran 2021/2022. Hutan mangrove di pantai Kecamatan Cukuh Balak mempunyai arti yang sangat penting baik sebagai suatu ekosistem maupun sebagai sumber daya alam. Keberadaan hutan mangrove di Cukuh Balak ini mulai mengalami perubahan disebabkan karena adanya Campur tangan manusia yang semakin meningkat terhadap hutan mangrove dalam rangka memenuhi kebutuhan atau meningkatkan kualitas hidupnya, Hutan Mangrove bisa digunakan sebagaih bahan belajar siswa SMAN 1 Cukuh Balak Kelas X pada materi Keanekaragaman Hayati.
\end{abstract}

Kata Kunci : Pengembangan Model Pembelajaran, Keanekaragaman Hayati, Mangrove

Abstract: The objectives of the research: (1) produce a learning model product for Exploring the Environment on Biodiversity as a Learning Resource for Class X at SMAN 1 Cukuh Balak, (2) determine the level of practicality of the Biodiversity learning model based on the Mangrove Ecosystem and (3) determine the level of effectiveness of the learning model Biodiversity based on Mangrove Ecosystems. Research and development is research that is used in developing a learning model for Biodiversity based on the Mangrove Ecosystem as a Class X Learning Resource at SMAN 1 Cukuh Balak in the 2021/2022 academic year. Mangrove forest on the coast of Cukuh Balak District has a very important meaning both as an ecosystem and as a natural resource. The existence of the mangrove forest in Cukuh Balak is starting to change due to increasing human intervention in the mangrove forest in order to meet the needs or improve the quality of life, the Mangrove Forest can be used as learning material for students of SMAN 1 Cukuh Balak Class X on Biodiversity material.

Keyword : Learning Model Developement, Biodiversity, Mangrove.

How To Cite:

Apridayani,. Hening Widowati, Achyani. 2022. Pengembangan Model Pembelajaran Jelajah Alam Sekitar (JAS) pada Materi Keanekaragaman Hayati sebagai Sumber Belajar Kelas X di SMAN 1 Cukuh Balak. BIOLOVA 3(1). 46-51 
Pendidikan adalah hak dari setiap manusia. Tidak hanya untuk orang kaya atau miskin, semua orang berhak mengenyamnya. Cara memperoleh pendidikanpun macam macam dan dimanapun bisa diperolehnya. Pendidikana adalah upaya manusia untuk memperoleh sebuah status dalam hidupnya yang lebih bermakna. Dalam suatu pendidikan terdapat satu bagian yang di sebut pembelajaran.

Berdasarkan UU No.20 Tahun 2003 (Sisdiknas, pasal 3) bahwa fungsi dan tujuan pendidikan nasional berfungsi menjadikan manusia yang beriman dan bertaqwa kepada Tuhan Yang Maha Esa dengan mengembangkan kemampuan watak serta peradaban bangsa yang bermartabat dalam rangka mencerdaskan kehidupan bangsa serta mengembangkan potensi peserta didik berakhlak mulia, sehat, berilmu, cakap, kreatif, mandiri dan menjadi warga negara yang demokratis serta bertanggung jawab. Dengan adanya tujuan Pendidikan tersebut maka sekolah diharapkan bisa melaksanakan proses pembelajaran yaitu guru bukan saja sebagai teacher center melainkan siswalah sebagai student center sehingga pembelajaran dapat berjalan dengan lancar.

Seorang guru harus mampu membawa Proses Pembelajaran menjadi sebuah wadah bagi siswa untuk mengembangkan kreatifitas dan inovasinya. Masalahnya saat ini adalah kurangnya minat dan daya serap siswa dalam Proses belajar Mengajar yang hanya focus dalam Kelas saja. Oleh sebab itu, seorang guru pun harus bisa membawa siswanya untuk belajar dari alam sehinggga keterkaitan emosi siswa dengan alam akan tertuang dalam Pembelajaran tersebut. Alam dan lingkungan dapat dimanfaatkan sebagai sumber belajar yang memiliki peranan penting dalam ketercapaian proses pembelajaran di sekolah. Berkaitan dengan alam dan lingkungan sebagai sumberdaya alam maka perilaku manusia yang cenderung tidak peduli, dapat diubah menjadi prilaku yang peduli yaitu dengan cara dalam melalui jalur pendidikan.

Melalui proses belajar mengajar yang bermuatan pendidikan dengan memanfaatkan alam sekitar, siswa diarahkan dan dibimbing untuk memanfaatkan lingkungan sekolah, menjadi lingkungan sekolah yang asri, yang ditunjang dengan fasilitas sekolah yang memungkinkan menyadarkan siswa agar terbentuknya etika lingkungan. Dengan siswa diajak belajar sambil berinteraksi dengan alam dan lingkungan, diharapkan rasa cinta dan peduli lingkungan akan tertanam dalam diri siswa.

Guru bisa mengembangkan berbagai model model pembelajaran yang variasi dalam pembelajaran. Pengembangan Model Pembelajaran ini sangat bisa membantu guru dalam menginovasi pembelajaran. Guru bisa memanfaatkan model model pembelajaran sebagai acuan untuk melakukan proses belajar mengajar dan menciptakan suasana PBM yang asik dan menyenangkan.

Dewasa ini Pelajaran Biologi bisa menerapkan pembelajaran yaitu salah satunya mengembangkan pembelajaran pada materi Keanekaragaman Hayati berbasis JAS. Pada dasarnya materi ini bisa memanfaatkan alam sekitar seperti Ekosistem pantai terutama Hutan Mangrove.

Wilayah pesisir dan lautan merupakan tumpuan harapan yang memiliki peranan yang sangat penting bagi kehidupan dan penghidupan bangsa 
Indonesia. Kedua wilayah tersebut merupakan lahan kedua bagi pembangunan Indonesia di masa mendatang. Wilayah teritorial Indonesia sekitar $63 \%$ yang kaya dan beragam dengan sumber daya alam dan jasa- jasa lingkungannya merupakan pesisir dan lautan yang memiliki, antara lain hutan mangrove, terumbu karang, perikanan, bahan tambang, jasa perhubungan dan pariwisata.

Hutan mangrove merupakan salah satu sumber daya alam wilayah pesisir yang penting. Keberadaannya sebagai penahan abrasi pantai, penahan lumpur dan sedimen berupa limbah limbah beracun yang dibawa oleh aliran air permukaan. Karakteristik khas pada Ekosistem mangrove ini sebagai tempat bermacam macam biota perairan sebagai daerah asuhan dan tempat mencari makan, daerah pemijahan dan pembesaran. Mangrove menyediakan bahan baku industri yang dapat dimanfaatkan antara lain sebagai kayu chip, kayu arang dan kayu bangunan sehingga bernilai ekonomis bagi manusia. Kayu mangrove juga dimanfaatkan oleh masyarakat untuk kayu bakar. Menurut Dahuri (1995) berdasarkan data yang ada luas areal mangrove yang terdapat hampir diseluruh pantai-pantai di Indonesia, kurang lebih 3,24 juta hektar.

Hutan Mangrove melindungi garis pantai, memperkaya perairan pesisir, mendukung perikanan pesisir, menghasilkan hasil hutan yang bermanfaat, menjadi habitat berbagai jenis fauna, dan sebagai tempat berkembangnya industri ekowisata .

Hutan mangrove di pantai Kecamatan Cukuh Balak mempunyai arti yang sangat penting baik sebagai suatu ekosistem maupun sebagai sumber daya alam. Keberadaan hutan mangrove di Cukuh Balak ini mulai mengalami perubahan disebabkan karena adanya Campur tangan manusia yang semakin meningkat terhadap hutan mangrove dalam rangka memenuhi kebutuhan atau meningkatkan kualitas hidupnya, Hutan Mangrove bisa digunakan sebagai bahan belajar siswa SMAN 1 Cukuh Balak Kelas X pada materi Keanekaragaman Hayati.

Dalam kaitannya dengan sumber belajar biologi, seorang guru berusaha mencari dan menemukan contoh konkrit dari suatu materi pembelajaran untuk memudahkan siswa memahami dan menguasai pelajaran yang sedang dipelajari. Dalam proses belajar mengajar perlu diadakan pengembangan dengan melalui media maupun sumber belajar yang nyata. Yang dimaksud sumber belajar dalam pelajaran biologi adalah berupa benda hidup maupun benda mati serta peristiwa yang mengandung masalah tertentu.

Pernyataan pelaksanaan proses belajar mengajar biologi dalam mencapai tujuan pembelajaran masih kurang dalam memanfaatkan objek-objek belajar yang nyata, sehingga penelitian im diharapkan dapat memberikan sumbangan pemikiran terhadap pelaksanaan proses belajar mengajar biologi pada bahan kajian Keanekaragaman Hayati.Dengan mengembangkan Model Pembelajaran Keanekaragaman hayati berbasis Mangrove bisa digunakan sebagai bahan belajar pada kelas X.

Proyek penelitian dan pengembangan yang bertujuan untuk menciptakan pembelajaran keanekaragaman hayati berbasis mangrove. Penelitian ini menggunakan model pengembangan Research and development, khususnya tahapan yang diidentifikasi oleh Setyosari (2010:201): (1) identifikasi tujuan pengajaran, (2) 
analisis pengajaran, (3) identifikasi perilaku awal/karakteristik siswa, (4) perumusan tujuan kinerja, (5) mengembangkan tes referensi benchmark, (6) mengembangkan strategi pengajaran, (7) mengembangkan dan memilih alat pengajaran, dan (8) merancang dan menerapkan penilaian formatif. Beberapa ahli dan validator bekerja sama untuk memvalidasi model pembelajaran yang dibuat dalam penelitian ini. Untuk tahun ajaran, subjek penelitian adalah siswa kelas $\mathrm{X}$ SMAN 1 Cukuh Balak.

Analisis data menggunakan statistik deskriptif untuk menganalisis data kualitatif dan kuantitatif. Data kuantitatif dianalisis dengan menggunakan teknik analisis yang telah ditentukan, seperti analisis validasi model pembelajaran ahli model pembelajaran menggunakan rumusan Khabibah dalam Yamasari, Yuni (2010:3), analisis kepraktisan model pembelajaran menggunakan rumus Hobri (2010:54), dan analisis kepraktisan model pembelajaran. Rumusan Hobri dalam H., Fiqih Nur dkk (2014:114) digunakan untuk menilai keefektifan model pembelajaran, sedangkan data kualitatif dinilai dengan menggunakan model Miles dan Huberman dalam Sugiyono (2009:246).

Jelajah Alam Sekitar pada materi Keanekaragaman Hayati berbasis Mangrove sebagai sumber belajar Biologi Siswa SMAN 1 Cukuh Balak adalah adalah model pembelajaran dimana guru menyiapkan media pembelajaran untuk mengkonstruksi pengalaman dan temuan dari ide atau konsep Biologi, kemudian mengajak siswa ke lingkungan (place setting) untuk berdiskusi dan mengalami secara langsung baik secara individu maupun kelompok. , agar siswa lebih aktif dan menghargai lingkungan." Perumusan tujuan pengajaran dilakukan pada tahap identifikasi tujuan pengajaran, tergantung pada SK dan KD yang digunakan dalam pengembangan.

Model pembelajaran Jelajah Alam Sekitar pada materi keanekaragaman hayati berbasis mangrove. Peneliti melakukan analisis pembelajaran yang berlangsung di SMAN 1 Cukuh Balak pada tahap melakukan analisis pembelajaran. Dimana pembelajaran sebagian besar didasarkan pada model pembelajaran tradisional, yang menekankan instruktur sebagai

pusat pembelajaran selama proses belajar mengajar. Setiap siswa memiliki kemampuan berbeda dalam menghadapi pembelajaran. Agar siswa tetap aktif dibutuhkan arahan yang tepat dari guru demikian juga dengan siswa siswi Kelas X SMAN 1 Cukuh Balak ini merupakan siswa yang aktif dan mau diarahkan, agar keaktifan mereka digunakan pada tempat yang tepat. Dalam merumuskan tujuan diharapkan siswa lebih memahami konsep materi pembelajaran yang disampaikan oleh guru dengan sistem pembelajaran yang menarik dan tidak membosankan selama kegiatan belajar mengajar berlangsung. Sebagai tes acuan patokan dalam penelitan ini, peneliti menggunakan tes evaluasi hasil belajar berbentuk pilihan ganda 20 soal yang dibuat berdasarkan Kompetensi Inti (KI) dan Kompetensi Dasar (KD).

\section{SIMPULAN DAN SARAN}

Berdasarkan pada hasil penelitian
dan pembahasan, maka dapat
disimpulkan bahwa: 1) model
pembelajaran Jelajah Alam Sekitar pada
materi Keanekaragaman Hayati berbasis
Mangrove sebagai sumber belajar 
Biologi Siswa SMAN 1 Cukuh Balak adalah valid, 2) Jelajah Alam Sekitar pada materi Keanekaragaman Hayati berbasis mangrove sebagai sumber belajar Biologi Siswa SMAN 1 Cukuh Balak adalah teruji praktis, dan (3) respon siswa terhadap Jelajah Alam Sekitar pada materi Keanekaragaman Hayati berbasis Mangrove sebagai sumber belajar Biologi Siswa SMAN 1 Cukuh Balak adalah adalah sangat positif, presentase tingkat ketuntasan belajar siswa sudah tercapai sehingga model tersebut teruji efektif.

Dalam Penelitian ini saran yang diberikan adalah: (1) melakukan uji coba terlebih dahulu sebelum model Jelajah Alam Sekitar pada materi Keanekaragaman Hayati (2) pada saat pembelajaran perlu ditekankan orientasi terhadap lingkungan/alam agar pemahaman materi dan konsepnya dapat diterima peserta didik secara maksimal, dan efisien.

\section{DAFTAR LITERATUR}

Amida Urfah Khoirun Nisa, dkk. 2019. Strategi Pengembangan Ekowisata Di Kawasan Konservasi Mangrove. JOURNAL OF MAQUARES Volume 8, h 169-176

Apridayani. 2003. Hubungan Tingkat Pendidikan Dengan Persepsi Masyarakat Tentang Keberadaan Hutan Mangrove Di Pantai Badak Muli Kecamatan Cukuh Balak. Skripsi tidak diterbitkan. Metro: FKIP UM Metro.

Badan Perencana Pembangunan Nasional. 1993. Biodiversity
Action Plan for Indonesia. Jakarta: BAPPENAS.

H., Fiqih Nur, dkk. 2014. Pengembangan Perangkat Pembelajaran Matematika pada Model "CORE" (Connecting, Organizing, Reflecting, Extending) dengan Pendekatan Kontekstual Pokok Bahasan Peluang untuk Siswa SMA Kelas XI. Universitas Jember: Kadikma Volume 5 Nomor 2.

Hobri. 2010. Metodologi Penelitian Pengembangan (Aplikasi pada Penelitian Pendidikan Matematika). Jember: Penasalsabila.

Jatna Supriatna. 2008. Melestarikan Alam Indonesia. Yayasan Obor Indonesia. Jakarta

Okid Parama Astirin. 2000. Permasalahan Pengelolaan Keanekaragaman Hayati di Indonesia. Dalam Majalah Biodiversitas. Vol 1 No 1 Januari 2000. Jakarta

Setyosari, Punaji. 2010. Metode Penelitian Pendidikan dan Pengembangan. Jakarta: Kencana Prenada Media Group.

Suhartini. 2009. Peran Konservasi Keanekaragaman Hayati Dalam Menunjang Pembangunan yang Berkelanjutan. Prosiding Seminar Nasional Penelitian Pendidikan dan Penerapan MIPA.Fakultas MIPA. UNY. Yogyakarta.

Sukara,E. 2003. Keanekaragaman Hayati (emas hijau), alternative 
bagi Indonesia keluar dari krisis multidimensi. Orasi Pengukuhan sebagai Ahli Peneliti Utama Bidang Mikrobiologi. Pusat Penelitian Bioteknologi-LIPI.

Bogor

Yamasari, Yuni. 2010. Pengembangan Media Pembelajaran Matematika Berbasis ICT yang Berkualitas. Artikel disajikan dalam Seminar Nasional Pascasarjana X-ITS, sSurabaya, 4 Agustus 2010.

Zuhud EAM, Haryanto. 1994. Pelestarian Pemanfaatan Keanekaragaman Tumbuhan Obat Hutan Tropika Indonesia. Fakultas Kehutanan IPB, Bogor. 
$52 \mid$ Apridayani,. Hening Widowati, Achyani. 2022. Pengembangan Model Pembelajaran..... 